\title{
Brasil-Estados Unidos: desafios de um relacionamento assimétrico
}

\section{LUIZ A. P. SOUTO MAIOR*}

Este artigo não pretende retraçar o curso das relações entre o Brasil e os Estados Unidos ao longo do tempo. Tampouco se propõe examinar os vários temas que compõem a atual agenda bilateral. Pretende apenas fazer - com ênfase nos problemas atuais, vistos à luz da posição de cada um dos dois países no quadro regional e mundial - uma reflexão sobre alguns dos desafios com que se depara, em seu relacionamento com a maior potência regional e mundial, um grande país emergente como o Brasil. Assim, dos temas que compõem a atual agenda bilateral, só a integração econômica hemisférica recebeu, pelo seu valor exemplificativo daquele relacionamento, atenção um pouco mais detida. Quanto ao passado, as referências limitaram-se praticamente ao período de após-Guerra e àquilo que foi considerado relevante para a compreensão do presente, em particular algumas diretrizes mais duradouras da política externa de um ou de outro país.

A política de Washington em relação à América Latina - em cujo quadro geral se insere necessariamente o relacionamento com o Brasil - tem, nas palavras de Federico Gil, "constantly pursued two objectives. The first has been to exclude from the western hemisphere extracontinental rival or hostile powers. The second has been to secure the dominant politico-economic presence of the United States in the region." ${ }^{\text {. }}$

A Doutrina de Monroe, enunciada pouco mais de um ano depois da proclamação da nossa independência, pode ser considerada o primeiro anúncio público de tal orientação pelo governo de Washington. Ao advertir as nações européias de que toda tentativa de recolonizar as repúblicas americanas recémindependentes ou de submetê-las ao sistema político dominante no Velho Mundo seria considerada como uma ameaça à paz e segurança dos Estados Unidos, o presidente americano explicitava o primeiro daqueles objetivos e deixava implícito o segundo. Pouco depois, o Brasil, ao tomar a iniciativa algo ingênua de sondar a disposição do governo americano em relação a uma possível "'liga ofensiva e defensiva com o Império, como parte do continente americano’, teve ocasião de comprovar a determinação de Washington de manter o caráter unilateral da iniciativa do Presidente Monroe”2. Os Estados Unidos não pretendiam uma parceria com 
os demais países do continente ou com qualquer deles individualmente, mas sim, deixar clara ao mundo sua disposição de defender a própria hegemonia na região.

É este caráter assimétrico que, de várias formas e com distintos graus de intensidade, marca até hoje as relações entre o Brasil - país em busca de maior espaço próprio na cena internacional - e a maior potência regional e mundial.

\section{$* * *$}

Do final da II Guerra Mundial até a implosão do império soviético, na segunda metade da década de 80 , o cenário internacional foi dominado pelo conflito entre as duas superpotências e pela rivalidade entre os respectivos sistemas políticoeconômicos. Direta ou indiretamente, as relações bilaterais entre os países eram condicionadas por essa bipolaridade. Assim, a política de Washington em relação à América Latina - e ao Brasil em particular - tornou-se um subproduto da Guerra Fria. Para os Estados Unidos, o importante era que todos os países ao sul do rio Grande tivessem regimes ideologicamente identificados com o Ocidente e que, subsidiariamente, fossem receptivos aos reclamos dos interesses econômicos americanos.

Para o Brasil, como para outros países periféricos, porém, o desenvolvimento econômico passara a ser um tema da mais alta prioridade. Assim, a relação entre ideologia e desenvolvimento e a importância relativa atribuída à primeira ou ao segundo tornaram-se, no contexto da Guerra Fria, questões maiores da nossa política interna e externa.

Terminado o conflito armado, o Brasil se manteve firmemente alinhado com os Estados Unidos, numa política de bloco que, em parte, era a seqüência natural da orientação adotada ainda antes do conflito, mas que refletia também a convicção de que esta seria a melhor maneira de conseguir da potência hegemônica o apoio necessário ao desenvolvimento do país. Conseguir o apoio externo ao seu projeto de desenvolvimento - pela remoção dos obstáculos existentes ou pela mobilização dos recursos necessários - passara a ser uma preocupação central da nossa política internacional.

Esta não era, entretanto, a percepção de Washington, que nunca atribuiu qualquer prioridade ao desenvolvimento econômico dos países periféricos, da América ou de outros continentes. Na época, o importante para os Estados Unidos era a reconstrução física - e no caso das ex-potências do Eixo, também a reestruturação política - dos países devastados pelo conflito, vistos como aliados necessários na Guerra Fria. Dentro deste enfoque, a América Latina não fazia jus a mais do que uma ajuda econômica modesta e a uma cooperação militar suficiente para alimentar a continuada simpatia das respectivas forças armadas pela luta contra o comunismo. Em suma, para Washington, tratava-se, como no passado, de assegurar que nada ameaçasse a preeminência americana na região, enquanto 
para o Brasil, o problema do desenvolvimento econômico passava a ocupar o primeiro plano.

A diferença entre as preocupações básicas - e, conseqüentemente, entre os objetivos centrais de política externa - das duas nações continha, assim, o germe de um conflito de interesses dificilmente contornável. Um conflito que, dado o enorme peso internacional dos Estados Unidos, tendeu a tornar-se, no Brasil, objeto de considerável controvérsia interna.

Com alguma simplificação, pode-se dizer que o debate se travava entre duas correntes de opinião. Havia os nacionalistas. Defendiam o desenvolvimento da indústria nacional com base no mercado interno, por meio da substituição de importações, para o que se faziam necessárias fortes barreiras tarifárias e nãotarifárias; restrições ao capital estrangeiro em algumas áreas consideradas cruciais para o desenvolvimento nacional, como o petróleo; a planificação econômica e a participação do Estado no processo produtivo, especialmente em setores considerados estratégicos, mas pelos quais a iniciativa privada não se interessasse com a presteza ou na forma julgadas adequadas, como o siderúrgico ou o energético. Politicamente, tendiam para a esquerda, embora só uma minoria chegasse a defender uma economia centralmente planificada e a socialização dos fatores de produção ou a identificar-se com a orientação internacional de Moscou. A eles se opunham os chamados entreguistas ou conservadores, conforme o grau de polidez do debate. Eram favoráveis ao liberalismo econômico e politicamente afinados, em matéria de política internacional, com as potências ocidentais.

Na prática, nossa política - tanto a internacional como a econômica oscilou ao longo do período, conforme a maior ou menor influência de uma ou outra corrente. De novo com alguma simplificação, pode-se dizer, porém, que as grandes linhas do receituário econômico dos nacionalistas prevaleceram até o fim da década de 80. Em contraste, nossa política externa tendeu a evitar atritos com Washington, buscando mais freqüentemente a conciliação entre os objetivos desenvolvimentistas nacionais e as diretrizes preconizadas pelos Estados Unidos.

Exemplo representativo de tal tendência foi a Operação Pan-Americana. Em 1958, frente às crescentes manifestações de insatisfação com a política americana em relação à América Latina e aos incidentes ocorridos por ocasião da visita do então Vice-Presidente Nixon a Caracas, o Presidente Kubitschek evitou criticar diretamente a orientação dos Estados Unidos. Em vez disso, lançou uma ampla operação diplomática com o objetivo de comprometer Washington com o processo de desenvolvimento da região, como se tal processo já fosse parte dos "ideais pan-americanos": "é chegada a hora de rever fundamentalmente a política de entendimento deste hemisfério e de proceder a um exame do que se está fazendo em prol dos ideais pan-americanos em todas as suas implicações”3. Seu objetivo era, conforme deixou claro em entrevista ao New York Times, "provocar um debate sobre o tema do subdesenvolvimento, que é a grande chaga do pan-americanismo"” . 
O pan-americanismo seria, segundo opinião emitida na mesma entrevista, "uma construção ideal, quase perfeita, nos seus aspectos políticos e jurídicos." O que preocupava o Presidente brasileiro é que, tendo avançado "milhas e milhas no terreno dos princípios, [o pan-americanismo] só avançou algumas escassas polegadas no terreno das realizações econômicas". ${ }^{5}$. Em suma, a idéia era conseguir apoio para o desenvolvimento econômico da América Latina por meio do relançamento da aliança com Washington, evitando o conflito.

Somente com a "política externa independente”, do Presidente Jânio Quadros, e a seguir de João Goulart, o Brasil assumiria uma atitude mais desenvolta em relação aos Estados Unidos.

Os acontecimentos de 1964 puseram fim, porém, àquela fase, inaugurando, com a primeira parte do regime militar, um período de alinhamento total com os Estados Unidos, marcado pelo rompimento de relações com Cuba e pela nossa participação na Força Interamericana de Paz em São Domingos. "Um tanto anacronisticamente, o Brasil se reinscreveria em 1964 no cenário internacional da Guerra Fria que, na realidade, já estava em mudança, com os primeiros movimentos do processo de détente". ${ }^{6}$.

Embora evitando gestos essencialmente simbólicos, como fora o caso da condecoração de "Che" Guevara, no período da "política externa independente", linha algo próxima desta última seria, entretanto, adotada pelo governo Geisel, mais de dez anos mais tarde, ainda em pleno regime militar. Iniciativas como, por exemplo, o reconhecimento do governo do MPLA, em Angola, ou o acordo de cooperação com a então República Federal da Alemanha, no campo da energia nuclear, ou ainda a decisão de votar a favor da resolução da Assembléia Geral da ONU que declarava o sionismo uma forma de racismo levaram a momentos de considerável fricção com Washington. Não se tratava, entretanto, de desvinculação ideológica com os Estados Unidos, mas da defesa de posições vistas como importantes para os interesses brasileiros, dentro da orientação que passaria a ser designada pela denominação algo canhestra de "pragmatismo responsável”. Os dois primeiros exemplos, inseriam-se em políticas claramente anunciadas logo no início do governo: a aproximação com as antigas colônias portuguesas, partes da “circunvizinhança de aquém e de além mar”, no primeiro caso; a busca de maior autonomia econômica e tecnológica, no segundo. O voto na ONU, do qual retrocederíamos anos depois, foi decidido pelo próprio Presidente ${ }^{7}$, no quadro geral da política de aproximação com os países árabes, tornada importante no contexto internacional que se seguiu à primeira crise do petróleo, em 1974.

Em suma, durante a Guerra Fria, a política externa brasileira tendeu, de modo geral, a alinhar-se com a dos Estados Unidos. Tal alinhamento foi quase total do ponto de vista ideológico, porém era às vezes qualificado pela percepção de um conflito entre a rígida política de bloco cobrada por Washington e os interesses de desenvolvimento econômico brasileiro. Eram situações que geralmente levavam à 
busca de um meio termo, como ocorreu no exemplo já citado da Operação PanAmericana. Só excepcionalmente - sobretudo nos dois períodos já assinalados, da “política externa independente” e do "pragmatismo responsável” - algumas divergências se tornaram mais explícitas.

Com a implosão do império soviético e o desaparecimento da própria URSS, as relações entre os dois países entraram numa nova fase, dominada por motivações e percepções distintas.

$$
* * *
$$

O triunfo do Ocidente na Guerra Fria não foi apenas uma vitória política da Aliança Atlântica. Talvez mais importante, foi a evidência de que, como sistema de produção, o capitalismo superara o chamado socialismo real, que cessou de ser oferecido ao mundo em desenvolvimento como alternativa de organização políticoeconômica. Isto teve pelo menos duas conseqüências relevantes para a presente reflexão.

No âmbito internacional, desapareceu o efeito aglutinador que a ameaça soviética, durante quatro décadas, exercera sobre os países do bloco ocidental. Os Estados Unidos continuam a ser a maior e mais desenvolvida economia do planeta e a manter a liderança política e militar no mundo, mas sua preeminência econômica se diluíra significativamente ao longo de quatro décadas. Não só seus aliados da OTAN e o Japão haviam aumentado consideravelmente sua participação no produto e no comércio mundiais, mas também os países em desenvolvimento de renda média passaram, no conjunto, a ocupar um espaço econômico que teria sido difícil de imaginar ao término da II Guerra Mundial. Durante a Guerra Fria, a ameaça externa representada pela União Soviética contribuíra para calar desavenças entre os aliados ocidentais, reforçando assim a unidade do bloco ocidental e a liderança americana sobre os seus aliados. Em última análise, ela ensejara, pois, uma situação esdrúxula, em que, com o desequilíbrio de contas correntes dos Estados Unidos, países enormemente prósperos, como o Japão e a então República Federal da Alemanha, passaram a financiar a liderança de outro sobre eles mesmos. Cessada - ou drasticamente reduzida - a ameaça, desapareciam os fundamentos de tal arranjo, embora não, no imediato, as suas conseqüências.

Na América Latina, Washington, com o fim da bipolaridade, já não podia cobrar solidariedade em nome da defesa contra a ameaça comum representada pelo "perigo comunista" - fosse tal "perigo", conforme o caso, real, percebido ou meramente forjado por motivos de oportunismo político. Assim, os objetivos de longo prazo identificados por Federico Gil - preeminência político-econômica e exclusão de potências extra-continentais hostis ou rivais - continuaram presentes, mas os meios de ação e as preocupações imediatas passaram a ser outros. 
Num mundo em que a economia tinha passado a ocupar posição central no dia a dia das relações internacionais, onde prosperava a tendência à formação de blocos econômicos regionais e onde os próprios Estados Unidos - antes o grande campeão do multilateralismo econômico - passara a participar de arranjos preferenciais de comércio, o caminho era claro. Embora sem qualquer relação causal, a assinatura do acordo de livre comércio com o Canadá e as negociações que levariam à formação da Área de Livre Comércio da América do Norte (NAFTA) praticamente coincidiram com o fim da Guerra Fria. Para Washington, era mister, porém, dar bases mais sólidas à hegemonia americana no continente, formalizando-a e legitimando-a política e juridicamente, bem como reforçar sua posição na rivalidade com outros países e blocos econômicos. Para tanto, um caminho óbvio seria vincular as demais nações do continente à grande economia americana. Tratava-se, evidentemente, de empresa bem mais ambiciosa e complexa, tanto pela amplitude dos tópicos envolvidos e pelo número de participantes quanto pelas resistências internas nos Estados Unidos, como ficara claro no penoso processo de aprovação da NAFTA pelo Congresso daquele país. A idéia, aliás, não era nova. Um século antes - num contexto internacional distinto, mas também marcado pela rivalidade dos Estados Unidos com os países europeus pelo mercado latino-americano -, Washington já propusera, na I Conferência Internacional Americana, em 1889-90, um esquema de integração econômica continental, que foi então vigorosamente combatido pela Argentina. Na época, aceitou-se, porém, a idéia de acordos comerciais bilaterais, com base na reciprocidade. Do ponto de vista americano, era mais trabalhoso, mas igualmente eficaz.

Do lado brasileiro, também se tinham produzido mudanças consideráveis. O modelo de substituição de importações - como vimos, parte do receituário econômico nacionalista - esgotara-se na década de 1970. Os anos 80 tinham sido em grande parte consumidos pela crise da dívida externa, que, fora a aproximação com a Argentina, deixou pouco espaço para a ação construtiva na área internacional. Ao iniciar-se a década de 90, impunha-se, pois, um esforço de reformulação econômica e política num mundo em transição. De um lado, como já assinalado, o fim da Guerra Fria transformara o cenário internacional. Ao Brasil cabia, pois, criar novos espaços de manobra num mundo já livre do rígido sistema de blocos que caracterizara o período anterior, explorando inclusive possíveis conflitos de interesses entre as grandes potências e pontos de afinidade com países periféricos de maior expressão. De outro, cabia reformular o modelo econômico que durante décadas nos assegurara uma alta taxa de crescimento econômico, procurando conciliar as exigências do nosso desenvolvimento com a necessidade de uma maior inserção do país na economia internacional, inescapável num mundo crescentemente globalizado. O que se deu não foi, porém, a busca de tal conciliação, mas sim a importação acrítica de um receituário concebido para servir ao interesse das grandes potências econômicas. 
Em 1990, com o governo Collor, iniciou-se um processo de atabalhoada abertura da economia brasileira e, a partir do Plano Real, estruturou-se "uma política econômica que - de maneira tão coerente que quase se poderia supor deliberada - conduziu o país à sua atual situação de total dependência externa. Deste ponto de vista e até a decisão de deixar flutuar o câmbio, seus aspectos mais relevantes foram, resumidamente:

1. Abertura acordada e unilateral do mercado brasileiro às importações, como forma de coibir a elevação dos preços, mas sem as cautelas necessárias para mitigar seus efeitos sobre a nossa balança comercial ou a indústria nacional;

2. Manutenção de um real sobrevalorizado, o que acentuou os efeitos da abertura comercial e contribuiu para aumentar a vulnerabilidade das empresas brasileiras frente à competição externa;

3. Altas taxas de juros, necessárias para sustentar a sobrevalorização cambial, mas que tiveram como efeitos colaterais estimular adicionalmente o endividamento externo das empresas e sobrecarregar as finanças públicas com o serviço de uma dívida em rápida expansão;

4. Política fiscal frouxa, com déficits crescentes, tornados inevitáveis por uma combinação de ausência de reformas pertinentes (tributária, previdenciária etc.) e dos já assinalados efeitos fiscais negativos da política de altas taxas de juros." 8

O que se verificou foi, pois, uma coincidência pouco feliz. No âmbito internacional, desapareceram as pressões diretamente ligadas à Guerra Fria, as questões econômicas ganharam maior importância relativa e as divergências entre as grandes potências tornaram-se mais explícitas. Em tese, abria-se, assim, maior espaço de manobra para os grandes países periféricos, especialmente para aqueles que, até a implosão do império soviético, tinham estado ideologicamente mais vinculados à política de blocos e, portanto, mais limitados em sua atuação externa. De modo geral, parecia haver, pois, condições favoráveis para aqueles países assumirem uma atitude mais assertiva na defesa dos seus interesses de desenvolvimento econômico. Para tanto era mister, porém, que eles tivessem uma visão própria daqueles interesses, procurando seguir uma política econômica consentânea com tal percepção e manter sua vulnerabilidade externa dentro de limites compatíveis com uma nova assertividade. Conforme já assinalado, nada disso aconteceu, porém, no Brasil. Como, já no fim do século, observaria Thomas Skidmore, o país parecia "imerso ... num clima generalizado de conformismo", numa fase em que "age como se não houvesse mais possibilidade de descobrir novos caminhos." Citando uma frase do Presidente Fernando Henrique Cardoso "Não há alternativa para a nossa política econômica” -, ele assinala que "existe esse sentimento geral no Brasil, e também em outros países em desenvolvimento, 
de que só há uma política certa. É a política que vem de Washington. Não se procura uma solução brasileira, ou mexicana, ou chilena”’ . E foi esta abulia criativa na busca de caminhos próprios que levou o país à adoção de uma política econômica desnacionalizante e colocou freqüentemente nossas divergências com os Estados Unidos como mera defesa de interesses tópicos, em vez de situá-las na moldura mais ampla dos grandes objetivos nacionais, dos quais, em última análise, elas decorrem.

$$
* * *
$$

Ao iniciar-se o século XXI, os dois maiores países das Américas encontramse, pois, em suas relações bilaterais, diante de desafios que podem não apenas influenciar de forma duradoura a organização do espaço político e econômico do continente, mas também, no caso do Brasil, condicionar a posição do país no cenário mundial.

Embora não seja o único, o principal desafio para Washington em sua política em relação à América Latina é, no momento, a organização econômica do continente em uma grande área hemisférica de livre comércio. A idéia, lançada originalmente pelo então presidente republicano George Bush, em 1990, com a sua Iniciativa para as Américas, foi formalizada em 1994, quando a decisão de negociar a Área de Livre Comércio das Américas (ALCA) foi aprovada multilateralmente na Cúpula das Américas, em Miami, sob os auspícios do presidente democrata Bill Clinton. No tocante ao poder executivo americano é, pois, um projeto que tem uma sólida base bipartidária, apesar das resistências de setores importantes, como os sindicatos, e de parte do Congresso, que até hoje se tem recusado a conceder ao Presidente a fast track authority, sem a qual a conclusão das negociações sobre a ALCA se torna praticamente inviável. Há a expectativa de que o atual Presidente George W. Bush, filho do patrono da iniciativa original, faça um esforço sério para conseguir os necessários poderes do Legislativo.

Dado o enorme hiato quantitativo e qualitativo entre a economia americana e as dos países da América Latina, é difícil evitar a noção de que, se levada a cabo como proposta, a iniciativa de Washington resultaria na satelitização econômica com inescapáveis desdobramentos políticos - dos países latinos do continente, inclusive dos maiores, como Brasil e Argentina. A título meramente indicativo da ordem de magnitude das assimetrias envolvidas, recorde-se que, segundo um estudo sobre o assunto baseado em dados do começo da década passada, "o PIB dos Estados Unidos, por exemplo, é quase duzentas vezes o do Chile, e 13 vezes o do Brasil. O PIB per capita dos Estados Unidos é sete vezes o do México, do Brasil e da Argentina, e vinte vezes o do Mercado Comum Centro-Americano (MCCA)." ${ }^{10}$. E mais. Segundo outro estudo, a produtividade média do trabalho na 
indústria latino-americana era, em 1990, apenas 26,1\% da registrada nos Estados Unidos $^{11}$.

Do ponto de vista brasileiro, a ALCA também representa o maior desafio global das suas relações com os Estados Unidos, porém em sentido contrário àquele como é percebido em Washington: não se trata de algo a realizar, mas antes a evitar ou reformular. Se levado a cabo tal como originalmente concebido, o projeto americano teria sérias conseqüências de médio prazo e implicações ainda mais graves, econômicas e políticas, a longo prazo. Do lado positivo, uma abertura ampla e confiável dos mercados americano e canadense (entenda-se como tal a eliminação das barreiras tarifárias e não-tarifárias existentes e a coibição do estabelecimento de outras) poderia gerar uma considerável ampliação das nossas exportações para aqueles destinos. Em sentido contrário, abriria, porém, às exportações dos Estados Unidos o mercado brasileiro e o dos demais países latino-americanos. Isto teria um impacto direto sobre a indústria nacional, tirando-lhe considerável fatia tanto do mercado doméstico quanto do de alguns dos principais compradores das nossas manufaturas, que são os países da ALADI. Haveria assim um efeito quantitativo sobre a nossa produção industrial e um impacto qualitativo sobre a nossa economia, já que tenderíamos a perder terreno justamente naqueles setores de maior densidade tecnológica, onde temos menos condições de competir com americanos e canadenses. Com as restrições que uma área de livre comércio imporia à nossa política industrial, haveria uma tendência, no mínimo, ao congelamento das atuais vantagens comparativas entre os parceiros desenvolvidos e em desenvolvimento, frustrando-se as perspectivas de desenvolvimento econômico destes últimos. $\mathrm{Na}$ verdade, no caso brasileiro, é mais provável que houvesse mesmo uma deterioração, já que parte das vantagens competitivas de que hoje desfrutamos em mercados da ALADI e, particularmente, do Mercosul passariam a ser partilhadas com exportadores americanos, que em alguns setores, como já assinalado, provavelmente deslocariam o competidor nacional, com a conseqüente atrofia das indústrias respectivas. O fluxo de investimentos estrangeiros diretos também tenderia a ser afetado, seja pela desaparição - no caso do capital americano - do incentivo representado pelo interesse em saltar a barreira da tarifa externa comum (TEC) do Mercosul, seja porque o investimento extracontinental preferiria, em alguns setores, localizar suas unidades produtivas nos Estados Unidos. Em conseqüência, as relações comerciais e de investimento do Brasil com o resto do mundo, hoje geograficamente diversificadas, tenderiam a concentrar-se muito mais nos Estados Unidos, criando, dada a assimetria de poder entre os dois países, indesejáveis vínculos de dependência. Assim, concretamente, o maior desafio atual nas nossas relações com Washington é a atitude a tomar em relação à ALCA. Como evitar ou retardar por muito tempo o seu estabelecimento - hipótese de realização altamente improvável - ou como reformular a proposta inicial, de modo a evitar ou atenuar os principais inconvenientes acima sumariamente indicados? 
Para um país que tem como parte importante do seu patrimônio diplomático as boas relações com todos as demais nações da América do Sul, a tendência natural foi tentar criar ou aprofundar com elas laços de interesse e vínculos formais, de modo a aumentar, em benefício de todos, o poder de barganha comum frente aos Estados Unidos. Tal via não se tem mostrado, porém, à altura do objetivo visado. Nem os demais países sul-americanos se têm, na sua grande maioria, mostrado sensíveis bastante aos riscos do projeto americano nem tem sido possível consolidar e ampliar o Mercosul, peça-chave de tal estratégia, na medida e com a rapidez que seriam necessárias. Em conseqüência, Washington, percebendo Brasília em desvantagem, partiu para a contra-ofensiva, brandindo o vaticínio de que as restrições do Brasil à ALCA teriam como única conseqüência isolar o país no continente.

Trata-se de uma simplificação, que contém algum elemento de verdade, mas também muito de blefe diplomático. Na realidade, nenhum projeto abrangente para a América Latina poderia considerar-se bem sucedido sem a participação do Brasil. Assim, a não-adesão do nosso país à ALCA provavelmente não inviabilizaria o projeto de Washington, mas certamente comprometeria o seu êxito global. Deixar de fora do seu esquema hegemônico o maior país da região é algo que os Estados Unidos certamente prefeririam evitar, já que tal desfecho lhe negaria o maior fruto potencial da sua iniciativa. Que concessões - se algumas - estarão, porém, dispostos a fazer para não chegar a tal desenlace?

O papel-chave do nosso país em qualquer política de Washington para o conjunto da América Latina - mas sobretudo para a América do Sul - foi enfaticamente ressaltado num documento recentemente elaborado por uma forçatarefa independente patrocinada pelo Council on Foreign Relations: "Brazil is a major economic power and is a leader among advanced emerging markets. Brazil's economy is more than twice as large as Russia's, almost as large as China's, and twice India's. Brazil is the main player in South America, with over half of the region's GDP and population. Brazil is the second-largest market in the world for executive jets and helicopters; the second for cellular telephones and fax machines; the fourth for refrigerators; the fifth for compact discs; and the third for soft drinks. With purchasing power parity of over \$1 trillion, in 2001 Brazil will rank fifth in the world, after the United States, China, Japan and Germany. Brazil is the leader of Mercosul (...)and sees Mercosul as being of great importance for its future geopolitical as well as economic role in South America." ${ }^{12}$. Conseqüentemente, a força-tarefa recomenda que, não apenas em relação à ALCA, mas ao conjunto de suas políticas no continente, particularmente na América do Sul, Washington "consider Brazil as a major strategic partner, treating it accordingly. (...) A strategic relationship with Brazil becomes a strategic relationship with South America.”13.

Em síntese, no tocante ao maior e mais abrangente desafio nas atuais relações entre Brasília e Washington, muito depende de perguntas que talvez ainda 
não tenham sido claramente colocadas e para as quais, muito provavelmente, não haveria respostas precisas nas respectivas chancelarias. À luz dos seus interesses e aspirações econômicos e políticos de médio e longo prazos, que tipo de integração hemisférica - se alguma - Brasília consideraria aceitável? Caso um entendimento com Washington sobre a forma de tal integração se revele inviável e nossa posição de resistência não tenha o respaldo dos principais países sul-americanos, que alternativas realistas teria o Brasil? Do ponto de vista americano, quais seriam, para Washington, os objetivos centrais, mínimos e inegociáveis da ALCA? Dado o evidente interesse em contar com a participação do Brasil, que concessões os Estados Unidos poderiam fazer, com vistas a conciliar as posições dos dois países, sem sacrificar aqueles objetivos centrais? Valeria a pena adotar essa linha conciliatória, de modo a estabelecer uma parceria eqüitativa e duradoura entre Brasília e Washington, ou seria preferível manter a pressão, tentando isolar o Brasil, como o atual discurso político americano pareceria indicar?

Trata-se evidentemente de questões tão abrangentes que só o processo de negociação lhes poderá trazer respostas cabais, mas, do ponto de vista das políticas externas dos dois países, a simples resposta preliminar a algumas delas já representaria uma tomada de posição no tocante às relações bilaterais. Na verdade, tais respostas preliminares representariam, em relação às grandes questões nelas colocadas, hipóteses de trabalho indispensáveis à formulação das posições negociadoras brasileira e americana.

Para o Brasil, por motivos que acredito ter deixado claros, a participação em uma área de livre comércio com os Estados Unidos tenderia a comprometer, a longo prazo, interesses brasileiros fundamentais. O desejável, portanto, seria que a ALCA nunca chegasse a se materializar. Como, entretanto, o mais provável parece ser que o Congresso americano termine, mais cedo ou mais tarde, por conceder ao Presidente a fast track authority, é de prever-se que Washington venha a ter condições de estabelecer uma área de livre comércio que abranja, além da NAFTA, a América Central, o Caribe e boa parte dos países sul-americanos. Nesta hipótese, a segunda das perguntas acima formuladas seria crucial - que alternativas realistas teria o Brasil? É claro que tal desenvolvimento não isolaria o nosso país em relação ao resto do mundo, mas o colocaria em posição de evidente desvantagem no trato econômico e, por via de conseqüência, também político com a grande maioria dos países americanos. E não parece realista esperar uma aproximação com a União Européia de molde a compensar a desvantagem econômica no âmbito regional, para não mencionar a perda de capacidade de liderança política na América do Sul. Escapa ao escopo deste artigo examinar a fundo as perspectivas que se nos apresentam, porém o cenário mais provável é fascinante e de alto risco. Ao que tudo indica, teremos de desenvolver uma estratégia complexa e delicada, em que nosso trunfo principal será a importância do Brasil tanto para os demais países latino-americanos como para o êxito pleno da própria ALCA. 
Do lado americano, também será necessário chegar a algumas respostas tentativas ou hipóteses de trabalho. Em última análise, optar pela alternativa conciliatória mencionada na última pergunta poderia significar o início de uma parceria que - dadas a assimetria de poder entre os parceiros, a tradição de hegemonia do mais forte e o nível das legítimas aspirações do mais fraco - tenderia a ser árdua, às vezes áspera, mas provavelmente frutífera e duradoura. Tal opção só se justificaria, porém, se Washington estivesse disposto a estabelecer, com os demais países do continente, um novo tipo de cooperação, na qual os Estados Unidos aceitariam a posição de primus inter pares e não mais de senhor das Américas. Como indicação de uma mudança em relação ao passado, tal atitude teria repercussões sobre toda uma gama de problemas hemisféricos, alguns só remota ou indiretamente relacionados com a integração econômica regional. Esta é a hipótese mais desejável, mas, ao que tudo indica, a menos provável.

$* * *$

Foi justamente pelo seu caráter abrangente, ilustrativo da percepção que cada um dos dois países tem dos seus interesses e da sua posição atual, bem como das suas aspirações, no cenário mundial, que esta breve reflexão se deteve na questão da integração hemisférica. Evidentemente, há toda uma gama de outros assuntos - regionais e mundiais - onde os dois países, de acordo com as suas capacidades, deverão interagir, embora as posições respectivas nem sempre sejam convergentes. A defesa da democracia nas Américas, o combate ao crime organizado - especialmente o narcotráfico e a lavagem de dinheiro -, a reforma das Nações Unidas e do sistema financeiro internacional são apenas alguns exemplos. A maneira como os dois se disporão a cooperar ou, alternativamente, a administrar suas divergências dependerá, porém, da percepção que cada um tenha da sua própria posição atual e futura no continente e no mundo e de como perceba as do outro. Neste sentido, a atitude de Brasília e de Washington no tocante à integração econômica continental poderá ser altamente reveladora para ambos.

Para o Brasil, a opção mais racional, embora não necessariamente a mais provável no governo atual, seria resistir às pressões americanas, inclusive à tentativa de isolá-lo dos demais países do continente. Por outro lado, a proximidade das eleições de 2002 torna aleatória qualquer previsão quanto à nossa conduta diplomática futura. Cabe, pois, especular sobre a conduta de Washington. Como já vimos, há, em tese, no tocante ao Executivo americano, apoio bipartidário para o estabelecimento de uma área hemisférica de livre comércio. Caberá à nossa diplomacia avaliar mais claramente, ao longo das negociações já em curso, os objetivos mínimos perseguidos pelos Estados Unidos com o seu projeto de integração continental. Se a proposta da ALCA visa à consolidação e legitimação da hegemonia americana no continente e, ao mesmo tempo, a melhor situar os Estados Unidos 
em sua competição econômica com países ou grupos de países extra-continentais, o conflito de interesses fundamentais com o Brasil tenderá a tornar-se cada vez mais claro e a hipótese de uma parceria - mesmo assimétrica e tormentosa, como aventado acima - entre Brasília e Washington, crescentemente remota. Não se trataria, neste caso, de conciliar choques de interesses limitados, mas sim de administrar uma divergência estratégica. Os custos, sobretudo para o Brasil, seriam certamente elevados, porém inevitáveis. Infelizmente, na ausência de evidências em contrário, ao analista familiarizado com a orientação histórica da política americana em relação à América Latina esta parece a alternativa mais provável. Neste caso, nos demais tópicos de interesse declarado dos Estados Unidos e do Brasil, as iniciativas de Washington também deveriam ser percebidas como tendo um viés intervencionista e dominador - e tratadas com a inevitável desconfiança daí decorrente. Admitidas, pois, as hipóteses de uma política hegemônica continental americana, de um lado, e de uma disposição de resistência do lado brasileiro, do outro, o relacionamento bilateral tenderia a ser não apenas assimétrico, mas também conflitivo. Cabe esperar que tal hipótese, certamente desgastante e indesejável, não se concretize...

Fevereiro de 2001

\section{Notas}

1 GIL, Federico G., The Kennedy-Johnson Years, in United States Policy in Latin America, John D. Martz (ed.), University of Nebraska Press, 1989, pág. 3.

Souto Maior, Luiz A. P., O Pan-Americanismo e o Brasil, Revista do Instituto Histórico e Geográfico Brasileiro, vol. 154 (1993), pág. 332. Juscelino KubitscheK - Carta ao Presidente dos Estados Unidos da América, 28 de maio de 1958. Operación Pan-Americana - Compilación de Documentos - I, Rio de Janeiro, Presidência da República - Serviço de Documentação, 1958, pág. 12. Traduzido do texto espanhol. Juscelino KubitscheK, entrevista ao New York Times, 6 de junho de 1958. Op. cit., pág. 64. Traduzido do texto espanhol. Idem, págs. 66 e 67. Traduzido do texto espanhol.

SeIXAs CoRrea, Luiz Felipe de, As relações internacionais do Brasil em direção ao ano 2000, in Temas de Política Externa Brasileira, Gelson Fonseca Júnior e Valdemar Carneiro Leão (org.), Brasília, 1989, pág.227.

7 Segundo depoimento do ex-Presidente, tomado muitos anos depois, o Itamaraty teria sido favorável à abstenção, atitude que lhe parecera, entretanto, "uma covardia. (....) Estou convencido até hoje de que o sionismo é racista”. V. D’Araujo, Maria Celina e Castro, Celso, Ernesto Geisel, Fundação Getúlio Vargas Editora, 3 a edição, 1997, pág. 341. Souto MaIor, Luiz A. P., Estabilidade, globalização e dependência, in Carta Internacional, no. 71, janeiro de 1999, USP, São Paulo. Entrevista de Thomas SKIDMORE, historiador americano, brasilianista e diretor do Centro de Estudos Latino-Americanos da Brown University, à revista "Veja", 19 de abril de 2000. \& NAFTA: o Brasil e a integração hemisférica, José Olympio Editora, 1995, pág. 145. 
11 Svarzman, Gustavo, La Argentina y el Mercosur ante el proceso de integración hemisférica, citado em Borón, Atílio A., Alca, Mercosur y la hegemonia norteamericana in CARrion, Raul K. M. e Vizentini, Paulo Fagundes (org.), A Crise do Capitalismo Globalizado na Virada do Milênio Editora da Universidade/UFRGS, 2000, pág. 138.

12 A Letter to the President and a Memorandum on U. S. Policy Toward Brazil - Statement of an Independent Task Force Sponsored by the Council on Foreign Relations, 14/2/2001, pág. 6. Idem, p. 5.

\section{Resumo}

$\mathrm{O}$ artigo analisa alguns dos desafios com que o Brasil se depara no relacionamento com os Estados Unidos desde o final da Segunda Guerra Mundial. Durante a Guerra Fria, o Brasil tendeu a se alinhar ideologicamente aos Estados Unidos enquanto buscava o desenvolvimento. Com o fim da Guerra Fria percebese a adoção de uma política desnacionalizante e de defesa de interesses tópicos nas divergências com os Estados Unidos. No século XXI, o desafio será a integração econômica. Nesse contexto, a ALCA, caso se concretize, trará a necessidade de administrar uma divergência estratégica entre os dois países.

\section{Abstract}

The article analyses some of the challenges Brazil has faced in its relationship with the United States since the end of the Second World War. During the Cold War, Brazil struggled to develop while it tended to be ideologically aligned to the United States. After the end of the Cold War, Brazil pursued denationalization policies and defended some minor interests against the United States. Economic integration is the challenge on the 21th century. In this context, the FTAA - Free Trade Area of Americas - will make it necessary for this two countries to administrate strategic differences, if it comes to reality.

Palavras-chave: Brasil. Estados Unidos. Relações Bilaterais. Integração. Key words: Brazil. United States. Bilateral Relations. Integration. 